\title{
Streptococcus pneumoniae Serotypes Associated with Death, South Africa, 2012-2018
}

\author{
Annelies Müller, Jackie Kleynhans, Linda de Gouveia, Susan Meiring, \\ Cheryl Cohen, Lucy Jane Hathaway, ${ }^{1}$ Anne von Gottberg, ${ }^{1}$ for GERMS-SA
}

The Streptococcus pneumoniae polysaccharide capsule plays a role in disease severity. We assessed the association of serotype with case-fatality ratio (CFR) in invasive pneumococcal disease (IPD) and meningitis in South Africa, 2012-2018 (vaccine era), using multivariable logistic regression by manual backward elimination. The most common serotypes causing IPD were 8 and 19A. In patients $<15$ years of age, serotypes associated with increased CFR in IPD, compared with serotype 8 and controlling for confounding factors, were $11 \mathrm{~A}, 13$, $19 F, 15 \mathrm{~A}$, and $6 \mathrm{~A}$. None of these serotypes were associated with increased CFR in meningitis. Among IPD patients $\geq 15$ years of age, serotype $15 \mathrm{~B} / \mathrm{C}$ was associated with increased CFR. Among meningitis patients of all ages, serotype 1 was associated with increased CFR. PCV13 serotypes 1, 3, 6A, 19A, and 19F should be monitored, and serotypes $8,12 \mathrm{~F}, 15 \mathrm{~A}$, and $15 \mathrm{~B} / \mathrm{C}$ should be considered for inclusion in vaccines to reduce deaths caused by S. pneumoniae.

Streptococcus pneumoniae is a leading cause of bac$\checkmark$ terial pneumonia and invasive pneumococcal disease (IPD), including meningitis, worldwide. These diseases especially affect the young, the elderly, and the immunocompromised (1). The pneumococcal capsular polysaccharide is a primary virulence factor used to classify the bacteria into $\geq 100$ different serotypes; it is the basis of pneumococcal conjugate vaccines (PCVs).

Author affiliations: University of Bern Graduate School for Cellular and Biomedical Sciences, Bern, Switzerland (A. Müller); University of Bern Institute for Infectious Diseases, Bern (A. Müller, L.J. Hathaway); National Institute for Communicable Diseases of the National Health Laboratory Service, Johannesburg, South Africa (J. Kleynhans, L. de Gouveia, S. Meiring, C. Cohen, A. von Gottberg); University of the Witwatersrand, Johannesburg (J. Kleynhans, S. Meiring, C. Cohen, A. von Gottberg)

DOI: https://doi.org/10.3201/eid2801.210956
Continued surveillance and choice of serotypes to include in future vaccination remains key to effective prevention strategies. PCV13, containing 13 different serotypes $(1,3,4,5,6 \mathrm{~A}, 6 \mathrm{~B}, 7 \mathrm{~F}, 9 \mathrm{~V}, 14,19 \mathrm{~A}$, $19 \mathrm{~F}, 18 \mathrm{C}$, and $23 \mathrm{~F}$ ), is the most commonly used pneumococcal vaccine; clinical trials are ongoing for new vaccines (2-5). Choosing which serotypes to include in vaccination strategies is important because serotype prevalence varies geographically, introduction of PCVs has changed serotype prevalence (6-8), and some serotypes are more common or are associated with more severe disease than other serotypes. In South Africa, before PCVs were introduced, the most commonly occurring serotypes in adults and adolescents $\geq 15$ years of age were $1,19 \mathrm{~A}, 4$, and 3; serotypes 1 and $19 \mathrm{~F}$ were associated with death (9). The association between serotype and disease outcome has also been shown in other epidemiologic studies (10-14) as well as in vivo models $(15,16)$. Serotypes repeatedly associated with elevated case-fatality ratio (CFR) in various countries are $3,6 \mathrm{~B}, 9 \mathrm{~N}, 11 \mathrm{~A}, 16 \mathrm{~F}, 19 \mathrm{~F}$, and 19A in adults (14) and 19F, 6A, and 3 in children (17). South Africa introduced the 7-valent PCV (PCV7) into the country's expanded program on immunization in 2009. In 2011, PCV7 was replaced by PCV13 (10). The current national vaccine program in South Africa recommends 3 doses of the PCV13 vaccine at 6 weeks, 14 weeks, and 9 months of age.

In this study, we aimed to determine which serotypes are associated with increased CFR in IPD and meningitis patients in the vaccine era in South Africa. We conducted the analysis for all IPD and for a subset of meningitis patients and in all ages as well as in 2 age groups of $<15$ and $\geq 15$ years. Our aims were to identify possible differences of serotypes associated with death in children and adults and between total

${ }^{1}$ These authors contributed equally to this article. 
IPD and meningitis and to compare the results with published data from the prevaccine era.

The Human Research Ethics Committee (Medical) of University of Witwatersrand (Johannesburg, South Africa) and relevant university and provincial ethics committees approved the GERMS-SA surveillance study (clearance nos. M140159, M081117, M021042, M180101). The Kantonale Ethikkommission Bern approved analysis of encoded South African patient data in Switzerland (project ID 2018-01172).

\section{Methods}

\section{IPD Surveillance}

We conducted IPD surveillance through GERMS-SA (https://www.nicd.ac.za/germs), an active laboratory-based surveillance program in South Africa for which information on bacterial and fungal pathogens including S. pneumoniae is collected. Specimens with laboratory-confirmed IPD from both the public and private sector are sent to the National Institute for Communicable Diseases (NICD) in Johannesburg as part of the GERMS-SA program. Demographic information is collected for all GERMS-SA cases. For 28 enhanced surveillance sites across South Africa, additional clinical information is collected on IPD patients, including outcome and HIV status, which we used for this study.

We performed pneumococcal serotyping by Quellung reaction using specific antiserum (Statens Serum Institute, https://en.ssi.dk). We determined serotype of nonviable isolates by PCR where possible. Serotype 15B and 15C are reported as 15B/C because of reported reversible switching between them (18).

\section{Study Population and Case Definition}

We included all IPD cases from enhanced surveillance sites from the GERMS-SA program during January 1, 2012-December 31, 2018, for which age, in-hospital outcome, and serotype information were available (Figure 1). We categorized 7 age groups: $<1$ year, 1-4 years, 5-14 years, 15-24 years, 25-44 years, 45-64 years, and $>64$ years. Of all IPD cases with serotype information available, we excluded cases if the patient was infected with $>1$ serotype or if the serotype was not in the currently available pneumococcal conjugate vaccines $(\mathrm{PCV})$ or the 23 -valent polysaccharide vaccine (PPSV23) and made up $<1 \%$ of isolates from cases. We also excluded cases if the serotype could not be distinguished because initial rapid antigen test confirming the presence of pneumococcal antigen was performed at initial laboratory but culture was negative and a PCR assay to identify serotype was negative or the serotype was not distinguishable within a group of serotypes. IPD was defined if $S$. pneumoniae was cultured from a patient sample of a normally sterile site (e.g., cerebrospinal fluid [CSF], blood, joint, or pleural fluid) or if the sample tested positive for S. pneumoniae by PCR. We defined a case as a meningitis case if the attending doctor diagnosed meningitis, regardless of the specimen (CSF, blood, or other) that was taken. We excluded repeat isolates from the same patient within 21 days of positive result. We used in-hospital death within 30 days of IPD episode as the measure for death outcome.

\section{Statistical Analysis}

We used a multivariable logistic regression by manual backward elimination. In a first step, we assessed the effect of age, HIV status, sex, province, race, year, diagnosis, and underlying medical condition using a univariate model. We included all significant variables $(\mathrm{p} \leq 0.2)$ in the multivariable logistic regression. In the multivariable model, we dropped nonsignificant factors $(p>0.05)$ with manual backward elimination. We conducted statistical analysis using Stata version 16.0 (StataCorp, https://www.stata.com). We performed all statistical tests with all IPD cases. We analyzed nonmeningitis IPD cases (nmIPD) as a supplementary analysis. We used only meningitis cases in our primary analysis because meningitis has a distinct clinical manifestation; the separate analysis enabled us to learn if the serotypes associated with CFR in all IPD cases are also those present in meningitis cases. In addition, we performed all analysis with all ages and also with age groups $<15$ years and $\geq 15$ years because these age groups are often described in literature; we separated by age group for easier comparison to previous studies. We considered results in the final model significant for $p \leq 0.01$ after Bonferroni correction. To compare CFR between serotypes, we chose serotype 8 as the reference because it was the most commonly occurring serotype in all IPD cases $(507 / 4,272,11.9 \%)$. Each of the other serotypes accounted for $<10 \%$ of total isolates.

\section{Results}

A total of 18,646 IPD patients were reported to the GERMS-SA surveillance program during 2012-2018 (Figure 1). Of these, 6,865 (36.8\%) patients were enrolled in the GERMS-SA enhanced surveillance program and 6,247 $(91.0 \%)$ of them had available outcome information. Of patients with outcome information, $6,228(99.97 \%)$ had age information. Samples from 5,103 (81.9\%) with known age were serotyped; of those, $4,906(96.1 \%)$ yielded a valid serotype by Quellung 
or were positive for one of the 38 serotypes included in the multiplex PCR. Of those with valid serotypes, $4,656(94.9 \%)$ had distinguishable serotype data. Of the distinguishable serotype cases, 4,272 (91.8\%) cases

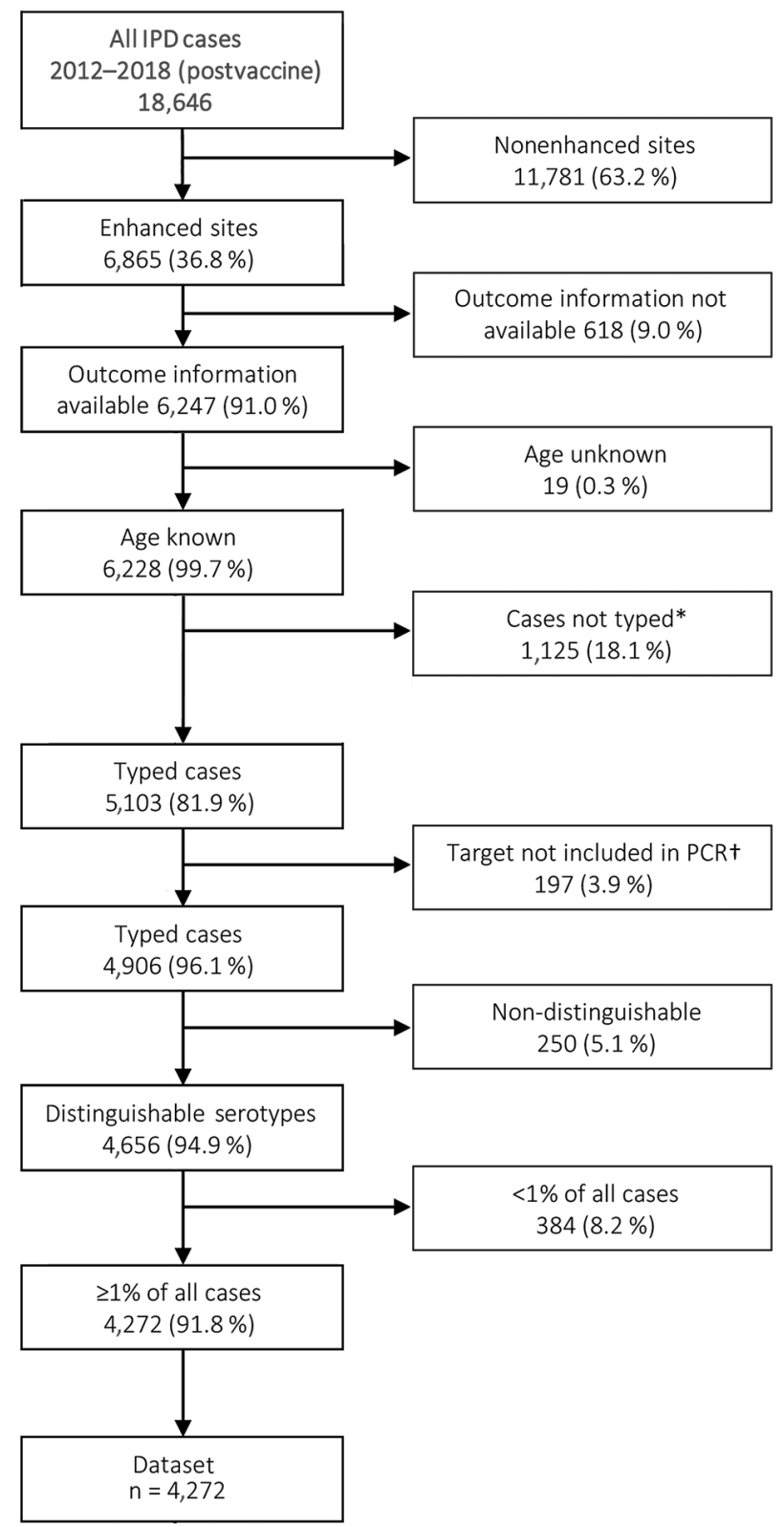

Figure 1. Flow diagram of cases included in the analysis of patients with IPD in South Africa, 2012-2018. Asterisk (*) indicates that cases were not typed for 1 of the following reasons: the case was identified by the laboratory information system data audits, $n=651$; the sample was positive for pneumococcal antigen detection but nonviable upon culture, $n=14$; the isolate was not received and thus serotyping not possible, $n=379$; or sample was nonviable and PCR negative, $n=81$. Dagger $(t)$ indicates that samples for which Quellung did not yield a valid result were prepared for PCR confirmation and serotyping if $P C R$ positive. If the multiplex PCR was negative for all 38 detectable serotypes, then the sample was excluded from analysis. IPD, invasive pneumococcal disease. had serotypes included in the PCV-13 vaccine or serotypes that comprised $>1 \%$ of all cases. The cases used in this study made up $22.9 \%$ of overall IPD cases $(4,272 / 18,646)$. The most represented age group was 25-44 years $(40.7 \%)$ (Table 1; Appendix 1 Figure 1, https://wwwnc.cdc.gov/EID/article/28/1/21-0956App1.pdf), which was similar to that of all cases, for which the most represented age group was also 25-44 years (Appendix 2 Table 1, https://wwwnc.cdc.gov/ EID/article/28/1/21-0956-App1.xlsx). Of those with known sex, $51.2 \%$ were female, was similar to the distribution of sex of all cases $(51.2 \%$ female of those with known sex) (Appendix 2 Table 1). Of those with known HIV status, $67.0 \%$ were HIV positive (Table 2; Appendix 1 Figure 2).

When we considered all IPD cases and all ages, the most common serotype identified was serotype $8(11.9 \%)$, followed by $19 \mathrm{~A}(8.9 \%), 12 \mathrm{~F}(8.8 \%)$, and 3 (6.8\%) (Table 2; Figure 2, panel A). This serotype distribution was similar to that of all 18,646 IPD cases from all GERMS-SA sites, in which the most common serotype identified was also serotype $8(7.2 \%)$, followed by $12 \mathrm{~F}(6.1 \%), 19 \mathrm{~A}(6.0 \%)$, and $3(4.2 \%)$ (Appendix 1 Figure 3; Appendix 2 Table 1). When considering all IPD cases and all ages, we found serotype 1 , $6 \mathrm{~A}, 19 \mathrm{~A}$, and $12 \mathrm{~F}$ to decrease in total number of isolates over time period of study (Figure 2, panel B). In patients $<15$ years of age, the most common serotype was serotype $8(14.0 \%)$, followed by serotype $1(7.3 \%)$, 19A $(6.7 \%)$, and 19F (6.3\%) (Table 2; Figure 2, panel A). Serotypes 12F, 3, 1, and 6A consistently decreased over time of study in this age group (Appendix 1 Figure 4 ). In patients $\geq 15$ years of age, the most common serotype was also serotype $8(11.1 \%)$, followed by $12 \mathrm{~F}(9.7 \%), 19 \mathrm{~A}(9.6 \%)$, and $3(7.9 \%)$ (Table 2; Figure 2 , panel A). In this age group, we found serotype 1 to consistently decrease over the time period of the study (Appendix 1 Figure 5). The overall CFR was $32.1 \%$ when considering all IPD cases. In patients $<15$ years of age, CFR was $22.1 \%$, and in those $\geq 15$ years of age, CFR was $35.5 \%$ (Tables 1, 2). Serotypes with the highest CFR in all IPD cases were $6 \mathrm{~A}(44.6 \%), 11 \mathrm{~A}$ $(43.8 \%)$, and $22 \mathrm{~F}(40.5 \%)$. In IPD patients $<15$ years, the serotypes with the highest CFR were serotype 11A (64.3\%), 22F (50.0\%), and 13 (40.0\%) (Figure 3). In IPD patients $\geq 15$ years of age, serotypes with the highest CFR were 5 (50.0\%), 6A (48.3\%), 15B/C (47.5\%), and 19F (43.1\%) (Figure 4). In nmIPD patients of all ages, the most common serotype was 19A, followed by 8 and 3 (Appendix 1 Figure 6). The serotype with the highest CFR in nmIPD in all ages was serotype 11A $(44.4 \%)$, followed by $10 \mathrm{~A}(36.9 \%)$ and $6 \mathrm{~A}$ and $19 \mathrm{~F}$ (both 35.4\%) (Appendix 2 Table 2). 
Table 1. Demographic characteristics of patients with invasive pneumococcal disease, South Africa, 2012-2018*

\begin{tabular}{|c|c|c|c|}
\hline \multirow[b]{2}{*}{ Variable } & \multicolumn{3}{|c|}{ No. (\%) patients } \\
\hline & Total IPD cases, $\mathrm{N}=4,272$ & Total $<15$ y, $n=1,095$ & Total $>15$ y, $n=3,177$ \\
\hline \multicolumn{4}{|c|}{ Year of specimen collection } \\
\hline 2012 & $792(18.5)$ & $237(21.6)$ & $555(17.5)$ \\
\hline 2013 & $679(15.99)$ & $193(17.6)$ & $486(15.3)$ \\
\hline 2014 & $601(14.1)$ & $194(17.7)$ & $407(12.8)$ \\
\hline 2015 & $603(14.1)$ & $138(12.6)$ & $465(14.6)$ \\
\hline 2016 & $585(13.7)$ & $136(12.4)$ & $449(14.1)$ \\
\hline 2017 & $553(12.9)$ & $106(9.7)$ & $447(14.1)$ \\
\hline 2018 & $459(10.7)$ & $91(8.3)$ & $368(11.6)$ \\
\hline \multicolumn{4}{|l|}{ Province } \\
\hline Eastern Cape & $272(6.4)$ & $55(5.0)$ & $217(6.8)$ \\
\hline Free State & $221(5.2)$ & $83(7.6)$ & $138(4.3)$ \\
\hline Gauteng & $1,636(38.3)$ & $417(38.1)$ & $1,219(38.4)$ \\
\hline KwaZulu-Natal & $685(16.0)$ & $180(16.4)$ & $505(15.9)$ \\
\hline Limpopo & $76(1.8)$ & $20(1.9)$ & $56(1.8)$ \\
\hline Mpumalanga & $172(4.0)$ & $33(3.0)$ & $139(4.4)$ \\
\hline Northern Cape & $214(5.0)$ & $36(3.3)$ & $178(5.6)$ \\
\hline North West & $119(2.8)$ & $26(2.4)$ & $93(2.9)$ \\
\hline Western Cape & $877(20.5)$ & $245(22.4)$ & $632(19.9)$ \\
\hline \multicolumn{4}{|l|}{ Sex } \\
\hline $\mathrm{F}$ & $2,184 / 4,267(51.2)$ & $505 / 1,093(46.2)$ & $1,679 / 3,174(52.9)$ \\
\hline$M$ & $2,083 / 4,267(48.8)$ & $588 / 1,093(53.8)$ & $1,495 / 3,174(47.1)$ \\
\hline Unknown & $5 / 4,272(0.1)$ & $2 / 1,095(0.2)$ & $3 / 1,095(0.1)$ \\
\hline Positive HIV status & $2,325 / 3,468(67.0)$ & $318 / 905$ (35.1) & $2,007 / 2,563(78.3)$ \\
\hline \multicolumn{4}{|l|}{ Age group } \\
\hline$<1 \mathrm{y}$ & $504(11.8)$ & $504(46.0)$ & NA \\
\hline $1-4 y$ & $319(7.5)$ & $319(29.1)$ & NA \\
\hline $5-14$ y & $272(6.4)$ & $272(24.8)$ & NA \\
\hline $15-24 y$ & $282(6.6)$ & NA & $282(8.9)$ \\
\hline $25-44 y$ & $1,738(40.7)$ & NA & $1738(54.7)$ \\
\hline $45-64$ y & $917(21.5)$ & NA & $917(28.9)$ \\
\hline$\geq 65 y$ & $240(5.6)$ & NA & $240(7.6)$ \\
\hline \multicolumn{4}{|l|}{ Race } \\
\hline Black & $3,452 / 4,160(83.0)$ & 939/1,066 (88.1) & $2,513 / 3,094(81.2)$ \\
\hline All others & $708 / 4,160(17.0)$ & $127 / 1,066(11.9)$ & $581 / 3,094(18.8)$ \\
\hline
\end{tabular}

When we analyzed only meningitis cases but considered all ages, we found that serotype 6A (61.9\%) had the highest CFR, followed by $16 \mathrm{~F}$ (59.0\%) and 19A (58.0\%). Serotype 6A also had the highest CFR when restricted to meningitis patients $<15$ years of age $(71.4 \%)$ (Figure 5$)$. In meningitis patients $\geq 15$ years of age, serotype 1 had the highest CFR (62.6\%) (Figure 6).

\section{Multivariable Analysis of In-Hospital Outcome in IPD}

On multivariable analysis, we found that in-hospital death was more likely when patients were infected with serotypes 6A (OR 2.1, 95\% CI 1.3-3.4) or 19F (OR 1.9, 95\% CI 1.2-2.9) compared with serotype 8. (Appendix 2 Table 3). Other factors significantly associated with in-hospital death on multivariable analysis were positive HIV infection (OR 1.3, 95\% CI 1.1-1.6), meningitis (OR 2.6, 95\% CI 2.2-3.0), and age. Compared with patients $5-14$ years of age, those at greatest risk were $<1$ year of age (OR 3.3, 95\% CI 2.0-5.5), 45-64 years (OR 5.6, 95\% CI 3.58.9 ), and those $\geq 65$ years (OR 8.6, 95\% CI 4.8-15.4)
(Appendix 2 Table 3). In nmIPD multivariable analysis, serotypes significantly associated with death compared with serotype 8 were 19F, 10A, and 23F (Appendix 2 Table 2).

When restricting analysis to patients $<15$ years of age, we found that those infected with the following serotypes were associated with increased in-hospital death compared with serotype 8: 11A (OR 11.1, 95\% CI 3.3-37.8), 13 (OR 4.3, 95\% CI 1.512.0), 19F (OR 3.5, 95\% CI 1.7-7.1), 6A (OR 3.2, 95\% CI 1.4-7.5), and 15A (OR 3.3, 95\% CI 1.6-6.9) (Tables $3,4)$. Other factors significantly associated with inhospital death on multivariable analysis were age (<1 year, OR 3.1 [95\% CI 1.9-5.1] vs. 5-14 years), meningitis (OR 1.8, 95\% CI 1.3-2.6), and province (Table 3). In the nmIPD multivariable analysis of patients $<15$ years of age, compared with serotype 8 , serotype $11 \mathrm{~A}$ was significantly associated with death (Appendix 2 Table 4).

When we restricted analysis to patients $\geq 15$ years of age we found that, compared with serotype 8 , those infected with serotype 15B/C (OR 2.1, 95\% CI 1.2-3.7) 
were more likely to die (Table 4). Other factors significantly associated with in-hospital death were sex (male, OR 1.3, 95\% CI 1.1-1.6), increasing age (45-64 years, OR 2.0, 95\% CI 1.4-2.9; $\geq 65$ years, OR 3.1, 95\% CI 1.8-5.2; vs. 15-24 years), and meningitis (OR 2.8, 95\% CI 2.3-3.4) (Table 4). In the nmIPD multivariable analysis of patients $\geq 15$ years, no serotypes were significantly associated with death when compared with serotype 8 (Appendix 2 Table 4).

\section{Multivariable Analysis of In-Hospital Outcome in Pneumococcal Meningitis}

Multivariable analysis indicated that meningitis patients infected with serotype 1 were more likely to die (OR 2.3, 95\% CI 1.2-4.1) than those infected with serotype 8 (Appendix 2 Table 3). Other factors significantly associated with increased in-hospital death were positive HIV status (OR 3.2, 95\% CI 2.2-4.6), underlying medical condition (OR 1.6, 95\% CI 1.1-2.1), and age.

\begin{tabular}{|c|c|c|c|}
\hline \multirow[b]{2}{*}{ Variable } & \multicolumn{3}{|c|}{ No. (\%) patients } \\
\hline & Total IPD cases, $\mathrm{N}=4,272$ & Total $<15 \mathrm{y}, \mathrm{n}=1,095$ & Total $\geq 15 \mathrm{y}, \mathrm{n}=3,177$ \\
\hline \multicolumn{4}{|l|}{ Serotype† } \\
\hline 4 & $223(5.2)$ & $15(1.4)$ & $208(6.6)$ \\
\hline $6 B$ & $64(1.5)$ & $30(2.7)$ & $34(1.1)$ \\
\hline $9 \mathrm{~V}$ & $41(1.0)$ & $10(0.9)$ & $31(1.0)$ \\
\hline 14 & $77(1.8)$ & $23(2.1)$ & $54(1.7)$ \\
\hline $18 \mathrm{C}$ & $48(1.1)$ & $11(1.0)$ & $37(1.2)$ \\
\hline $19 \mathrm{~F}$ & $178(4.2)$ & $69(6.3)$ & $109(3.4)$ \\
\hline $23 \mathrm{~F}$ & $136(3.2)$ & $57(5.2)$ & $79(2.5)^{\prime}$ \\
\hline 1 & $282(6.6)$ & $80(7.3)$ & $202(6.4)$ \\
\hline 3 & $290(6.8)$ & $39(3.6)$ & $251(7.9)$ \\
\hline 5 & $28(0.7)$ & $14(1.3)$ & $14(0.4)$ \\
\hline $6 \mathrm{~A}$ & $121(2.8)$ & $34(3.1)$ & $87(2.8)$ \\
\hline $7 F$ & $81(1.9)$ & $2(0.2)$ & $79(2.5)$ \\
\hline $19 A$ & 379 (8.9) & $73(6.7)$ & $306(9.6)$ \\
\hline 2 & $2(0.1)$ & 0 & $2(0.1)$ \\
\hline 8 & 507 (11.9) & $153(14.0)$ & 354 (11.1) \\
\hline $9 \mathrm{~N}$ & $127(3.0)$ & $15(1.4)$ & $112(3.5)^{\prime}$ \\
\hline $10 \mathrm{~A}$ & $121(2.8)$ & 37 (3.4) & $84(2.6)$ \\
\hline $11 \mathrm{~A}$ & $48(1.1)^{\prime}$ & $14(1.3)$ & $34(1.1)$ \\
\hline $12 \mathrm{~F}$ & $375(8.8)$ & 68 (6.2) & 307 (9.7) \\
\hline $15 B / C$ & $146(3.4)$ & $66(6.0)$ & $80(2.5)^{\prime}$ \\
\hline $17 F$ & $113(2.7)$ & $26(2.4)$ & $87(2.7)$ \\
\hline 20 & $19(0.4)^{\prime}$ & $6(0.6)$ & $13(0.4)$ \\
\hline $22 \mathrm{~F}$ & $111(2.6)$ & $12(1.1)$ & 99 (3.1) \\
\hline $33 \mathrm{~F}$ & $17(0.4)^{\prime}$ & $6(0.6)$ & $11(0.4)$ \\
\hline $16 \mathrm{~F}$ & $178(4.2)$ & $57(5.2)$ & $121(3.8)$ \\
\hline $15 \mathrm{~A}$ & 154 (3.6) & $50(4.6)$ & 104 (3.3) \\
\hline 13 & $91(2.1)$ & $20(1.8)$ & $71(2.2)$ \\
\hline $7 C$ & $86(2.0)$ & 27 (2.5) & 59 (1.7) \\
\hline $35 B$ & $105(2.5)$ & $53(4.8)$ & 52 (1.6) \\
\hline $23 \mathrm{~A}$ & $80(1.9)$ & 18 (1.6) & $62(2.0)$ \\
\hline $6 C$ & $44(1.0)$ & $10(0.9)$ & $34(1.1)$ \\
\hline \multicolumn{4}{|l|}{ Specimen } \\
\hline CSF & $1,223(28.6)$ & $328(30.0)$ & 895 (28.2) \\
\hline Blood & 2,728 (63.9) & 697 (63.7) & 2,031 (63.9) \\
\hline Other & $321(7.5)$ & $70(6.4)^{\prime}$ & $251(7.9)$ \\
\hline \multicolumn{4}{|l|}{ Diagnosis } \\
\hline Bacteremia without focus & $319(7.5)$ & $94(8.6)$ & $225(7.1)$ \\
\hline Lower respiratory tract infection & $2,352(55.1)$ & $551(50.3)$ & $1,801(56.7)$ \\
\hline Meningitis $\ddagger$ & $4,439(33.7)$ & $400(36.5)$ & $1,039(32.7)$ \\
\hline Other & $162(3.6)$ & $50(4.6)$ & $112(3.5)$ \\
\hline \multicolumn{4}{|l|}{ In-hospital outcome } \\
\hline Died & $1,369(32.1)$ & $242(22.1)$ & $1,127(35.5)$ \\
\hline Underlying conditions $\S$ & $1,352(31.7)$ & $428(39.1)$ & $924(29.1)$ \\
\hline \multicolumn{4}{|c|}{$\begin{array}{l}\text { *Data from GERMS-SA (https://www.nicd.ac.za/germs) enhanced surveillance sites. } \\
\text { †Serotypes appear in order of vaccine. The first } 7 \text { are in the PCV7 vaccine, the first } 13 \text { are in the PCV13 vaccine, the first } 23 \text { in the PPSV23 vaccine, } \\
\text { the rest are not included in a current vaccine. } \\
\text { †Meningitis cases include those diagnosed with meningitis and those with both meningitis and lower respiratory tract infections. } \\
\text { §Predisposing conditions defined as any one or more of the following: burns, chronic lung disease (including asthma, chronic obstructive pulmonary } \\
\text { disorder, cystic fibrosis), chronic liver disease, chronic renal disease, cardiac conditions (including valvular disease and heart failure), stroke, } \\
\text { neuromuscular diseases, cerebral palsy, metabolic diseases (including diabetes mellitus), head injury, surgery, cerebrospinal fluid leaks, ventricular } \\
\text { shunts, cochlear implants, primary immunodeficiency conditions, complement deficiency, immunosuppression treatment (steroids/chemo/cancer } \\
\text { treatment),protein-energy malnutrition, functional or anatomic asplenia (including sickle cell disease), malignancy, organ transplant, chromosomal } \\
\text { conditions (including Down syndrome), prematurity and aplastic anemia. }\end{array}$} \\
\hline
\end{tabular}



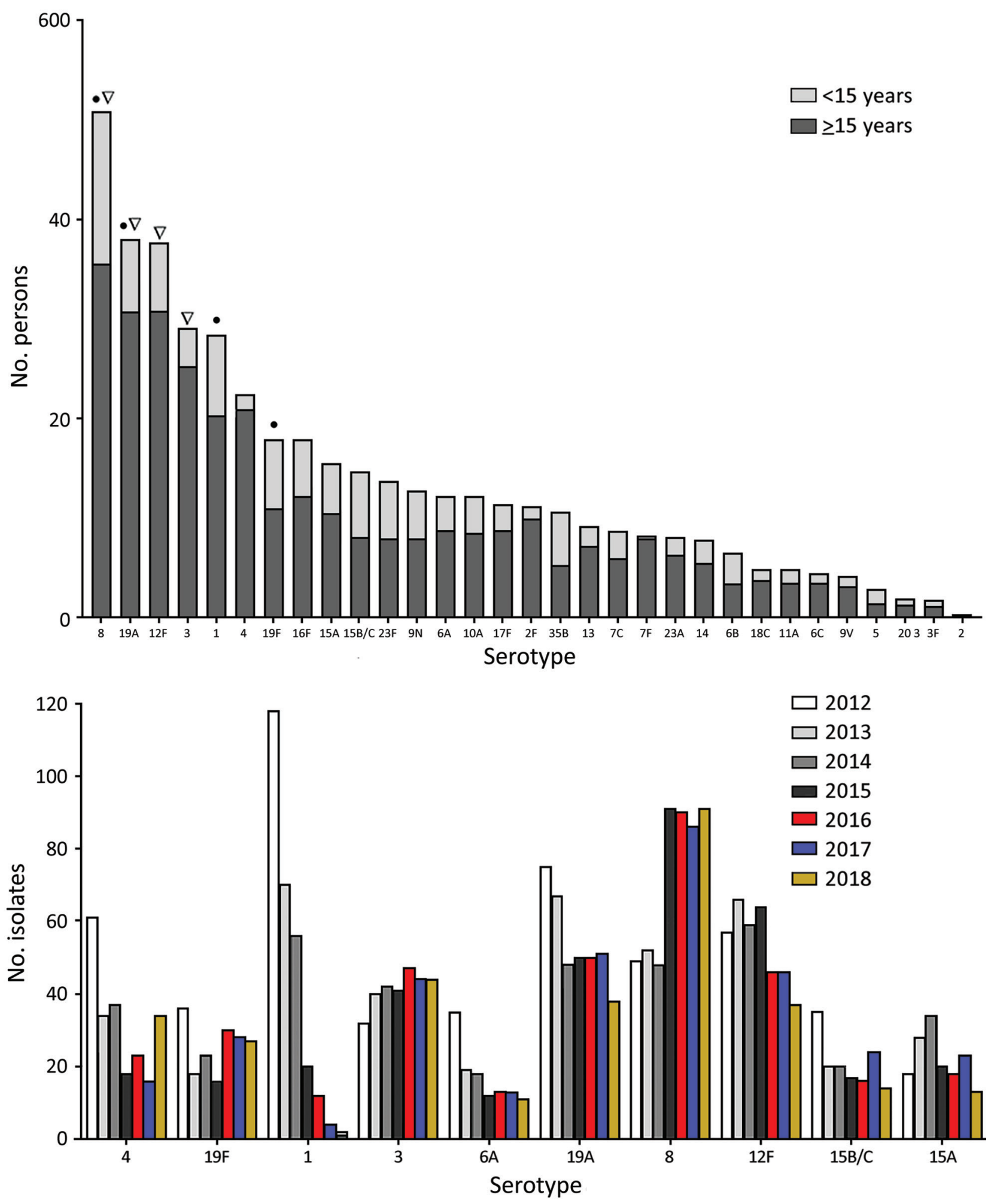

Figure 2. Number of isolates per serotype in invasive pneumococcal disease patients in South Africa, 2012-2018. A) Total number of isolates; serotype 8 was the most commonly isolated $(507,12 \%)$. Black dots indicate most common serotypes in patients $<15$ years of age; arrowheads indicate most common serotypes in patients $\geq 15$ years of age. B) Number of isolates per serotype per year of the 4 most common serotypes in the prevaccine era (1, 19A, 3, and 4) (9), the 4 most common in the vaccine era $(8,19 \mathrm{~A}, 12 \mathrm{~F}$, and 3$)$, and $6 \mathrm{~A}$ and 19F. The 7-valent pneumococcal conjugate vaccine was introduced in 2009, 13-valent in 2011. 


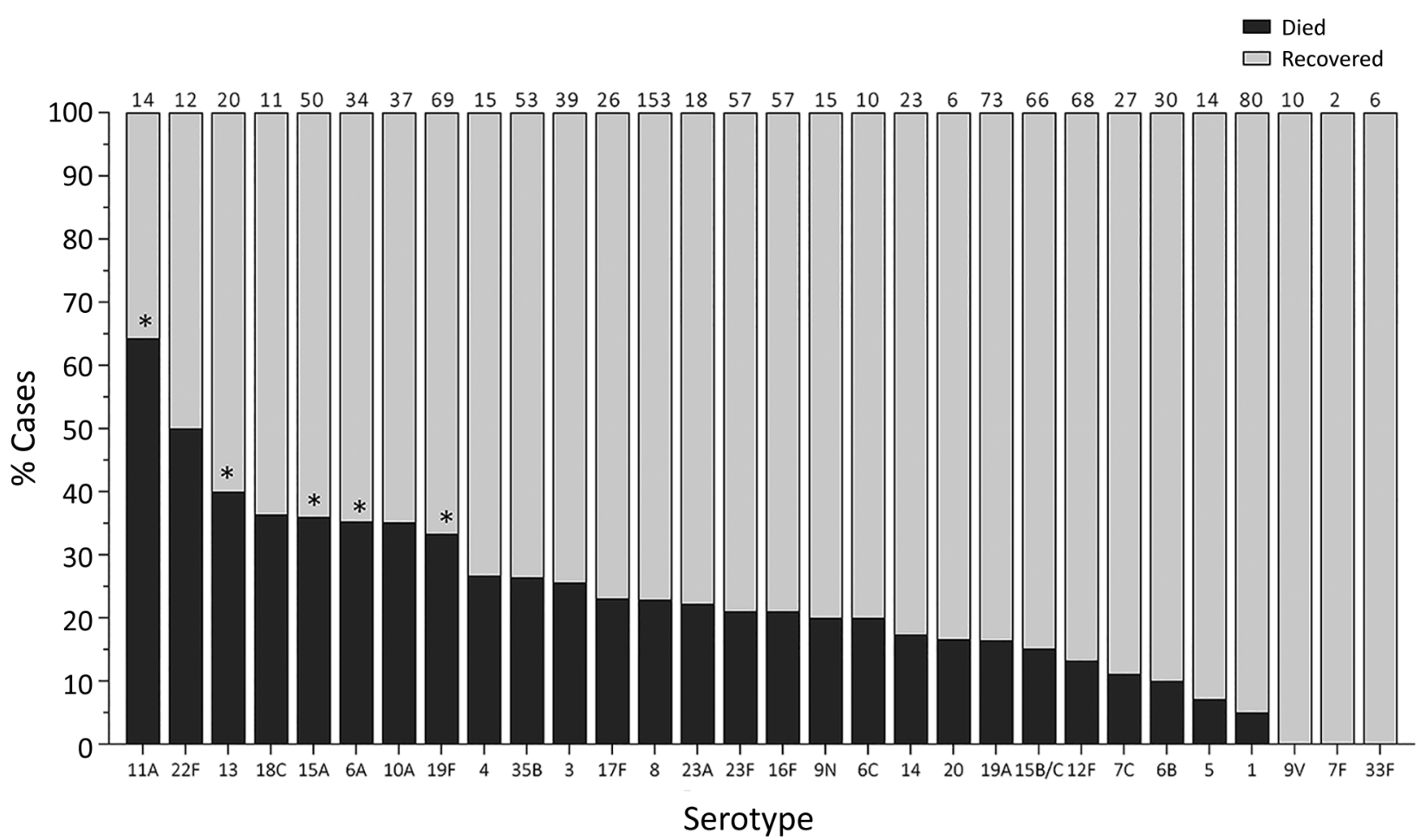

Figure 3. In-hospital outcome per serotype of IPD patients $<15$ years of age, South Africa, 2012-2018. Numbers above bars indicate number of cases per serotype. Asterisk $\left(^{*}\right)$ indicates serotypes significantly associated with increased in-hospital death upon multivariable analysis compared to serotype 8. IPD, invasive pneumococcal disease.

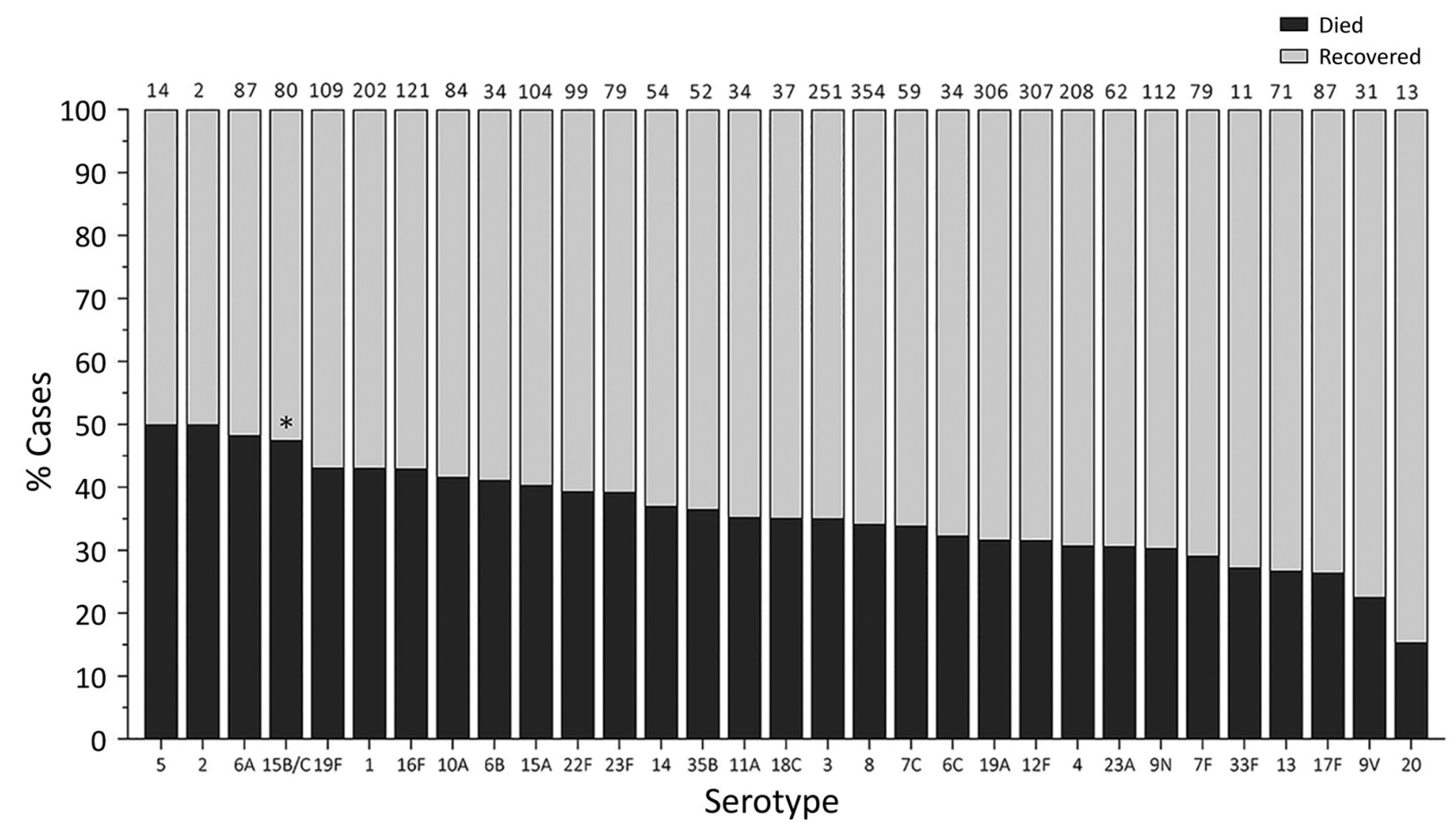

Figure 4 In-hospital outcome per serotype of IPD patients $\geq 15$ years of age, South Africa, 2012-2018. Numbers above bars indicate number of cases per serotype. Asterisk $\left(^{*}\right)$ indicates serotypes significantly associated with increased in-hospital death upon multivariable analysis compared to serotype 8. IPD, invasive pneumococcal disease. 
Compared with patients 5-14 years of age, those at greatest risk were patients < 1 year (OR 4.7, 95\% CI 2.210.3), 1-4 years (OR 4.3, 95\% CI 1.9-10.0), and 45-64 years (OR 7.0 95\%, CI 3.4-14.4) (Appendix 2 Table 3).

When we restricted meningitis cases to patients $<15$ or $\geq 15$ years of age, we did not find any serotypes significantly associated with increased in-hospital death compared with serotype 8 (Figure 5; Appendix 2 Table 5). Other factors significantly associated with increased odds for in-hospital death in patients $<15$ years of age were province, positive HIV status (OR 3.1, 95\% CI 1.5-6.3), and age ( $<1$ year, OR 5.0, 95\% CI 1.9-12.9; 1-4 years, OR 5.4, 95\% CI 2.0-14.4) (Appendix 2 Table 5). Other factors significantly associated with increased CFR in meningitis patients $\geq 15$ years were sex (male, OR 1.6, 95\% CI 1.2-2.2), positive HIV status (OR 3.5, 95\% CI 2.2-5.6), and underlying medical condition (OR 1.7, 95\% CI 1.2-2.6) (Appendix 2 Table 5).

\section{Discussion}

Nine years after PCV7 introduction and 5 years after PCV13 introduction in South Africa, the non-PCV13 serotype 8 is the most common serotype found in IPD patients followed by 19A, 12F, and 3. Serotype 1, a PCV13 serotype decreasing in total number over the study period, was associated with higher CFR than serotype 8 in analysis of meningitis cases including all ages. Serotype 6A was associated with higher CFR in the analysis of IPD for all ages, in particular in IPD cases of patients $<15$ years of age. In patients $\geq 15$ years of age, we found that serotype $6 \mathrm{~A}$ decreased in 2012 and 2013 but then stabilized until study end. Serogroup 15 non-PCV13 serotypes 15A and 15B/C were also associated with higher CFR than serotype 8 . Other factors that we found were independently associated with death in $>2$ analyses were HIV status, age, meningitis infection, year, and province.

Serotypes associated with death in the prevaccine era (2003-2008) in South Africa in patients $\geq 15$ years of age included serotypes 1 and 19F in IPD patients but no particular serotype in meningitis patients (19). Serotype 1, which is a PCV13 but not a PCV7 serotype, was associated with death in our analysis of meningitis cases of all ages in the vaccine era. Serotype 1 is associated with outbreaks of meningitis $(20,21)$. In studies from mainly prevaccine years (1990-2009) $(22,23)$, and particularly in a meta-analysis including studies from 1928-2010 (24), the risk for death from serotype 1 was found to be lower than that for other serotypes. In the prevaccine era, serotype 1 has been associated with a high invasive disease potential $(25,26)$ (studies from France, Alaska, and Iceland) and noted to be one of the most common IPD serotypes globally in children $<5$ years of age (27). These studies cover different time periods and geographic locations than ours; distinct serotype 1 lineages circulating in South Africa, as described in du Plessis et al. (28), could explain the differences we found in association with death. Similar to a previous study of serotype 1 epidemiology in South Africa in 2003-2013 (29), we notice a continued decline of overall numbers of serotype 1 IPD cases in patients $\geq 15$ years of age. The characteristics of serotype 1 pneumococci lineages and our results suggest that even though numbers are decreasing overall, this serotype should be monitored locally and globally in the future and the association of specific lineages with death and with meningitis should be analyzed.

Vaccines continue to play a crucial role in protection against pneumococcal disease. On the basis of our results in South Africa, we recommend protecting against the PCV13 serotypes 3, 6A, 19F, and $19 \mathrm{~A}$, as well as serotype 1 , and monitoring the nonPCV13 serotype 12F for its effects on pneumococcal disease. Serotype 6A in particular was associated with death in analysis of IPD of all ages and of IPD in patients $<15$ years of age. Serotype $19 \mathrm{~F}$ was associated with death in IPD patients in the vaccine era as well as in the prevaccine era (19); a component of both the PCV13 and PCV7 vaccines, serotype 19F seems to be associated with more severe disease both in our study and in previous studies $(14,24,30)$. Serotype 19A was the second most common serotype in IPD in both the prevaccine and the vaccine era; it is included in the PCV13 but not in the PCV7 vaccine and was noted to be one of the most important replacement serotypes in the United States in children $<5$ years of age (31). Serotype 3 (a PCV13 but not PCV7 serotype) and serotype 12F (a non-PCV serotype) were both among the 4 most common serotypes overall in our IPD study population; the total number of deaths was $\approx 100$ for each. Although we did not find either serotype 3 or $12 \mathrm{~F}$ independently associated with death in our analysis, the total numbers lead us to suggest monitoring these serotypes in the future.

Although serotype 1 was the most common serotype in the prevaccine era in South Africa (19), we found serotype 8 to be the most common in the current vaccine era. This finding in South Africa is similar to a recent report from Europe, North America, and Australia (32) and also a study summarizing serotypes globally (33). Including this serotype in new vaccine formulas could therefore reduce overall IPD cases. Serogroup 15 should be considered in new vaccine 


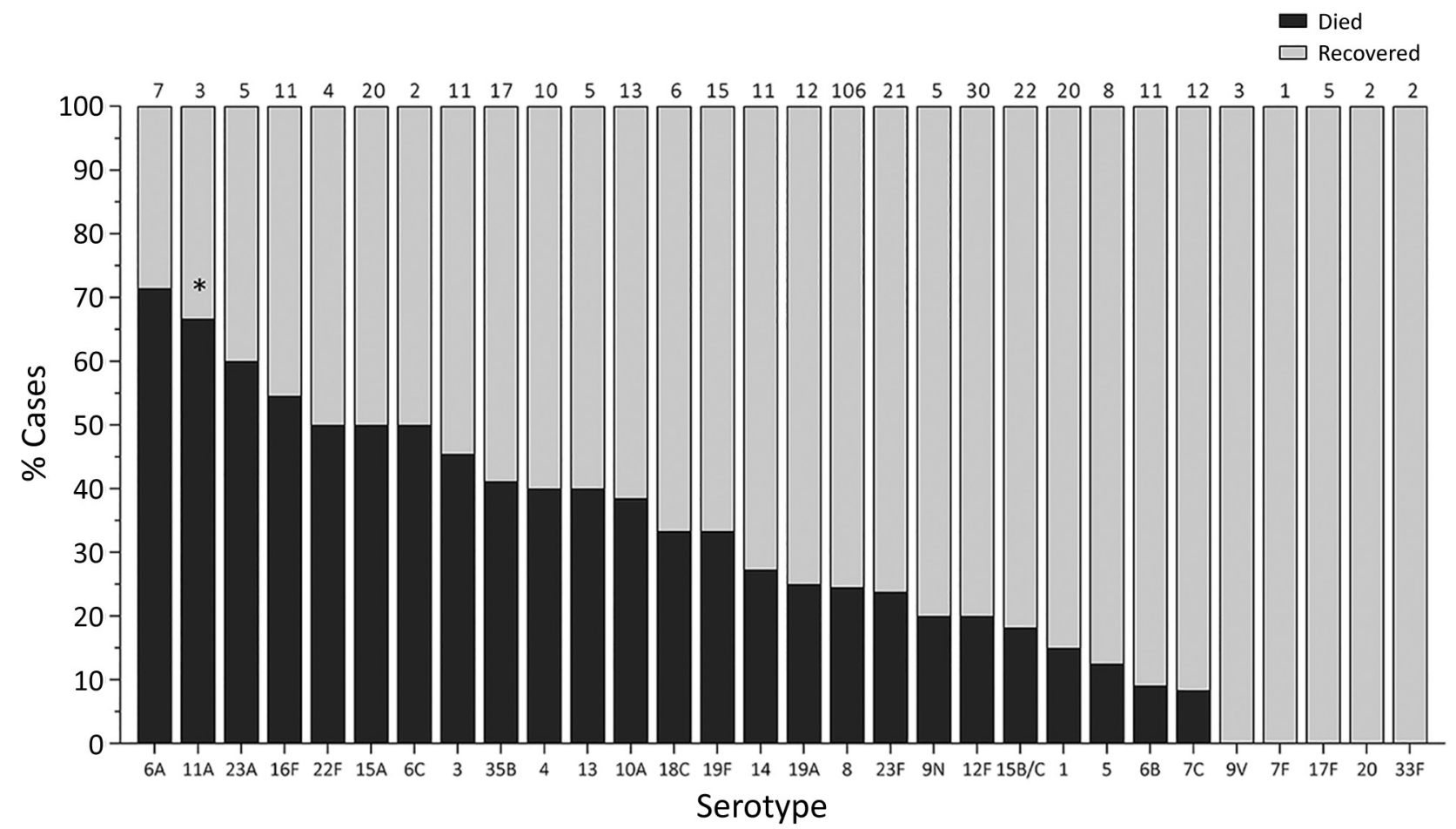

Figure 5. In-hospital outcome per serotype of meningitis patients $<15$ years of age, South Africa, 2012-2018. A case was defined as a meningitis case if the attending doctor diagnosed it as meningitis, regardless of the specimen type (cerebrospinal fluid, blood, or other) that was taken. Numbers above bars indicate number of cases per serotype. Asterisk ( $\left.{ }^{*}\right)$ indicates serotypes significantly associated with increased in-hospital death upon multivariable analysis compared to serotype 8. IPD, invasive pneumococcal disease.

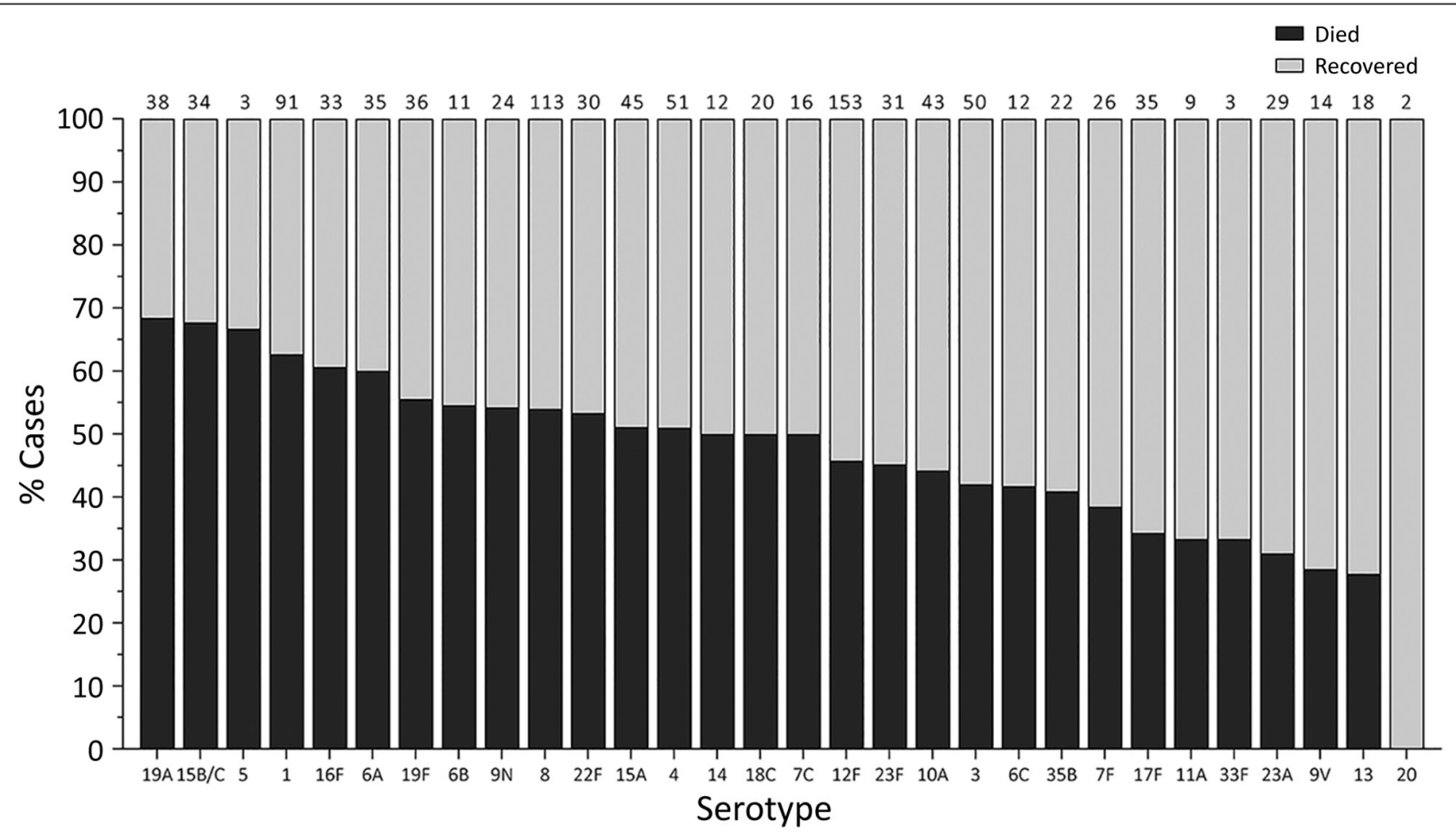

Figure 6. In-hospital outcome per serotype of meningitis patients $\geq 15$ years of age, South Africa, 2012-2018. A case was defined as a meningitis case if the attending doctor diagnosed it as meningitis, regardless of the specimen type (cerebrospinal fluid, blood, or other) that was taken. Numbers above bars indicate number of cases per serotype. Asterisk $\left(^{*}\right)$ indicates serotypes significantly associated with increased in-hospital death upon multivariable analysis compared to serotype 8 . IPD, invasive pneumococcal disease. 
Table 3. Multivariable analysis of factors associated with in-hospital death among patients $<15$ years of age with invasive pneumococcal disease, South Africa, 2012-2018*

\begin{tabular}{|c|c|c|c|c|c|}
\hline Risk factor & No. deaths/total no. (\%) & Unadjusted OR $(95 \% \mathrm{Cl})$ & $p$ value & Adjusted OR $(95 \% \mathrm{Cl})$ & $p$ value \\
\hline \multicolumn{6}{|l|}{ Serotype } \\
\hline 4 & $4 / 15(26.7)$ & $1.2(0.4-4.1)$ & 0.740 & $2.2(0.6-8.1)$ & 0.231 \\
\hline $6 \mathrm{~B}$ & $3 / 30(10.0)$ & $0.4(0.1-1.3)$ & 0.124 & $0.6(0.2-2.4)$ & 0.492 \\
\hline 14 & $4 / 23(17.4)$ & $0.7(0.2-2.2)$ & 0.556 & $1.2(0.4-3.9)$ & 0.777 \\
\hline $18 \mathrm{C}$ & $4 / 11(36.4)$ & $1.9(0,5-7)$ & 0.317 & $3.1(0.8-12.2)$ & 0.104 \\
\hline $19 \mathrm{~F}$ & $23 / 69$ (33.3) & $1.7(0.9-3.2)$ & 0.102 & $3.5(1.7-7.1)$ & $<0.001$ \\
\hline $23 \mathrm{~F}$ & $12 / 57(21.1)$ & $0.9(0.4-1.9)$ & 0.778 & $1.9(0.9-4.4)$ & 0.108 \\
\hline 1 & $4 / 80(5.0)$ & $0.2(0.1-0.5)$ & 0.002 & $0.6(0.2-1.8)$ & 0.328 \\
\hline 3 & $10 / 39(25.6)$ & $1.2(0.5-2.6)$ & 0.716 & $2.1(0.8-5)$ & 0.115 \\
\hline 5 & $1 / 14(7.1)$ & $0.3(0-2.1)$ & 0.201 & $0.3(0-2.1)$ & 0.200 \\
\hline $6 \mathrm{~A}$ & $12 / 34(35.3)$ & $1.8(0.8-4.1)$ & 0.135 & $3.2(1.4-7.5)$ & 0.008 \\
\hline $19 \mathrm{~A}$ & $12 / 73(16.4)$ & $0.7(0.3-1.4)$ & 0.267 & $1.2(0.5-2.6)$ & 0.646 \\
\hline 8 & $35 / 153$ (22.9) & Referent & Referent & Referent & Referent \\
\hline $9 N$ & $3 / 15(20.0)$ & $0.8(0.2-3.2)$ & 0.800 & $1.5(0.4-6)$ & 0.583 \\
\hline $10 \mathrm{~A}$ & $13 / 37(35.1)$ & $1.8(0.8-4)$ & 0.127 & $2.8(1.2-6.5)$ & 0.015 \\
\hline $11 \mathrm{~A}$ & $9 / 14(64.3)$ & $6.1(1.9-19.3)$ & 0.002 & $11.1(3.3-37.8)$ & $<0.001$ \\
\hline $12 \mathrm{~F}$ & $9 / 68(13.2)$ & $0.5(0.2-1.1)$ & 0.102 & $0.8(0.3-1.8)$ & 0.545 \\
\hline $15 \mathrm{~B} / \mathrm{C}$ & $10 / 66(15.2)$ & $0.6(0.3-1.3)$ & 0.197 & $1(0.5-2.3)$ & 0.941 \\
\hline $17 \mathrm{~F}$ & $6 / 26(23.1)$ & $1(0.4-2.7)$ & 0.982 & $1.8(0.6-5.2)$ & 0.260 \\
\hline 20 & $1 / 6(16.7)$ & $0.7(0.1-6)$ & 0.723 & $0.9(0.1-8.8)$ & 0.940 \\
\hline $22 \mathrm{~F}$ & $6 / 12(50.0)$ & $3.4(1-11.1)$ & 0.046 & $5(1.4-18.1)$ & 0.015 \\
\hline $16 \mathrm{~F}$ & $12 / 57(21.1)$ & $0.9(0.4-1.9)$ & 0.778 & $1.5(0.7-3.3)$ & 0.317 \\
\hline $15 \mathrm{~A}$ & $18 / 50(36.0)$ & $1.9(1-3.8)$ & 0.069 & $3.3(1.6-6.9)$ & 0.002 \\
\hline 13 & $8 / 20(40.0)$ & $2.2(0.9-5.9)$ & 0.102 & $4.3(1.5-12)$ & 0.006 \\
\hline $7 \mathrm{C}$ & $3 / 27(11.1)$ & $0.4(0.1-1.5)$ & 0.178 & $0.5(0.1-1.8)$ & 0.293 \\
\hline $35 \mathrm{~B}$ & $14 / 53(26.4)$ & $1.2(0.6-2.5)$ & 0.602 & $1.8(0.8-3.8)$ & 0.148 \\
\hline $23 \mathrm{~A}$ & $4 / 18(22.2)$ & $1(0.3-3.1)$ & 0.950 & $2(0.6-6.7)$ & 0.277 \\
\hline $6 \mathrm{C}$ & $2 / 10(20.0)$ & $0.8(0.2-4.2)$ & 0.834 & $1.6(0.3-8.6)$ & 0.579 \\
\hline \multicolumn{6}{|l|}{ Age group, $y$} \\
\hline$<1$ & $152 / 504(30.2)$ & $3.5(2.3-5.3)$ & $<0.001$ & $3.1(1.9-5.1)$ & $<0.001$ \\
\hline $1-4$ & $60 / 319(18.8)$ & $1.9(1.2-3)$ & 0.009 & $1.6(0.9-2.6)$ & 0.086 \\
\hline $5-14$ & $30 / 272(11.0)$ & Referent & Referent & Referent & Referent \\
\hline \multicolumn{6}{|l|}{ Sex } \\
\hline $\mathrm{F}$ & $124 / 505(24.6)$ & Referent & Referent & Referent & Referent \\
\hline$M$ & $117 / 588(20.0)$ & $0.8(0.6-1)$ & 0.065 & $0.7(0.5-1)$ & 0.055 \\
\hline \multicolumn{6}{|l|}{ HIV status } \\
\hline Negative & $111 / 587(18.9)$ & Referent & Referent & & \\
\hline Positive & $66 / 318(20.8)$ & $1.1(0.8-1.6)$ & 0.504 & & \\
\hline \multicolumn{6}{|l|}{ Diagnosist } \\
\hline Nonmeningitis & $129 / 695(18.6)$ & Referent & Referent & Referent & Referent \\
\hline Meningitis & $113 / 400(28.3)$ & $1.7(1.3-2.3)$ & $<0.001$ & $1.8(1.3-2.6)$ & $<0.001$ \\
\hline \multicolumn{6}{|l|}{ Yearł } \\
\hline 2012 & 40/237 (16.9) & Referent & Referent & & \\
\hline 2013 & $45 / 193$ (23.3) & $1.5(0.9-2.4)$ & 0.097 & & \\
\hline 2014 & $38 / 194$ (19.6) & $1.2(0.7-2)$ & 0.468 & & \\
\hline 2015 & $33 / 138(23.9)$ & $1.5(0.9-2.6)$ & 0.098 & & \\
\hline 2016 & $39 / 136(28.7)$ & $2(1.2-3.3)$ & 0.008 & & \\
\hline 2017 & $25 / 106(23.6)$ & $1.5(0.9-2.7)$ & 0.145 & & \\
\hline 2018 & $22 / 91(24.2)$ & $1.6(0.9-2.8)$ & 0.133 & & \\
\hline \multicolumn{6}{|l|}{ Province } \\
\hline Eastern Cape & $19 / 55$ (34.6) & $4.3(1.8-10.5)$ & 0.001 & $3.9(1.5-10.1)$ & 0.004 \\
\hline Free State & $9 / 83(10.8)$ & Referent & Referent & Referent & Referent \\
\hline Gauteng & $97 / 417(23.3)$ & $2.5(1.2-5.2)$ & 0.014 & $2.3(1.1-5)$ & 0.031 \\
\hline KwaZulu-Natal & $30 / 180(16.7)$ & $1.6(0.7-3.6)$ & 0.220 & $1.7(0.7-3.8)$ & 0.243 \\
\hline Limpopo & $3 / 20(15.0)$ & $1.5(0.4-5.9)$ & 0.605 & $1.1(0.3-4.9)$ & 0.855 \\
\hline Mpumalanga & $5 / 33(15.2)$ & $1.5(0.5-4.8)$ & 0.522 & $1.2(0.4-4.3)$ & 0.724 \\
\hline Northern Cape & $10 / 36(27.8)$ & $3.2(1.2-8.6)$ & 0.025 & $3.8(1.3-11.2)$ & 0.014 \\
\hline North West & $9 / 26(34.6)$ & $4.4(1.5-12.6)$ & 0.007 & $3.3(1.1-10.6)$ & 0.040 \\
\hline Western Cape & $60 / 245(24.5)$ & $2.7(1.3-5.6)$ & 0.010 & $2(0.9-4.5)$ & 0.085 \\
\hline
\end{tabular}


formulations, because we found 15B/C (IPD patients $\geq 15$ years) and $15 \mathrm{~A}$ (IPD patients $<15$ years) to be associated with death. To our knowledge, recent data of postvaccine dynamics of serogroup 15, as well as its association with CFR, are scarce. Savinola et al. (34) described the emergence of a 15A multidrug-resistant

Table 4. Multivariable analysis of factors associated with in-hospital death among patients $\geq 15$ years of age with invasive pneumococcal disease, South Africa, 2012-2018

\begin{tabular}{|c|c|c|c|c|c|}
\hline Risk factor & No. deaths/total no. (\%) & Unadjusted OR $(95 \% \mathrm{Cl})$ & $p$ value & Adjusted OR $(95 \% \mathrm{Cl})$ & $p$ value \\
\hline \multicolumn{6}{|l|}{ Serotype } \\
\hline 4 & $64 / 208(30.8)$ & $0.9(0.6-1.2)$ & 0.406 & $1.1(0.7-1.8)$ & 0.541 \\
\hline $6 B$ & $14 / 34(41.2)$ & $1.3(0.7-2.8)$ & 0.415 & $1.6(0.7-1)$ & 0.296 \\
\hline $9 \mathrm{~V}$ & $7 / 31(22.6)^{\prime}$ & $0.6(0.2-1.3)$ & 0.194 & $0.6(0.2-1.8)$ & 0.344 \\
\hline 14 & $20 / 54(37.0)$ & $1.1(0.6-2.1)$ & 0.681 & $1.5(0.8-3)$ & 0.236 \\
\hline $18 \mathrm{C}$ & $13 / 37(35.1)$ & $1(0.5-2.1)^{\prime}$ & 0.907 & $0.7(0.3-1.9)$ & 0.524 \\
\hline $19 \mathrm{~F}$ & $47 / 109(43.1)$ & $1.5(0.9-2.3)$ & 0.091 & $1.5(0.9-2.5)$ & 0.154 \\
\hline $23 \mathrm{~F}$ & $31 / 79(39.2)$ & $1.2(0.8-2.1)$ & 0.395 & $1.6(0.9-2.9)$ & 0.127 \\
\hline 1 & $87 / 202(43.1)$ & $1.5(1-2.1)$ & 0.038 & $1.7(1.1-2.7)$ & 0.017 \\
\hline 3 & $88 / 251$ (35.1) & $1(0.7-1.5)$ & 0.823 & $1.1(0.8-1.7)$ & 0.524 \\
\hline 5 & 7/14 (50.0) & $1.9(0.7-5.6)$ & 0.230 & $2.3(0.7-7.8)$ & 0.180 \\
\hline $6 \mathrm{~A}$ & $42 / 87$ (48.3) & $1.8(1.1-2.9)$ & 0.015 & $1.6(0.9-2.8)$ & 0.127 \\
\hline $7 F$ & $23 / 79(29.1)$ & $0.8(0.5-1.3)$ & 0.388 & $1(0.5-1.8)$ & 0.885 \\
\hline 19A & 97/306 (31.7) & $0.9(0.6-1.2)$ & 0.499 & $1.3(0.9-2)$ & 0.176 \\
\hline 2 & $1 / 2(50.0)$ & $1.9(0.1-31.1)$ & 0.644 & $4.5(0.3-74.4)$ & 0.288 \\
\hline 8 & $121 / 354(34.2)$ & Referent & Referent & Referent & Referent \\
\hline $9 N$ & $34 / 112(30.4)$ & $0.8(0.5-1.3)$ & 0.454 & $1.3(0.8-2.3)$ & 0.307 \\
\hline $10 \mathrm{~A}$ & $35 / 84(41.7)^{\prime}$ & $1.4(0.8-2.2)$ & 0.199 & $1.5(0.8-2.6)$ & 0.185 \\
\hline $11 \mathrm{~A}$ & 12/34 (35.3) & $1.1(0.5-2.2)$ & 0.896 & $0.9(0.3-2.7)$ & 0.881 \\
\hline $12 \mathrm{~F}$ & 97/307 (31.6) & $0.9(0.6-1.2)$ & 0.481 & $0.8(0.5-1.2)$ & 0.250 \\
\hline $15 B / C$ & $38 / 80(47.5)^{\prime}$ & $1.7(1.1-2.8)$ & 0.027 & $2.1(1.2-3.7)$ & 0.010 \\
\hline $17 \mathrm{~F}$ & $23 / 87$ (26.4) & $0.7(0.4-1.2)$ & 0.169 & $0.7(0.4-1.3)$ & 0.250 \\
\hline 20 & $2 / 13(15.4)$ & $0.4(0.1-1.6)$ & 0.177 & $0.3(0-2.8)$ & 0.309 \\
\hline $22 \mathrm{~F}$ & $39 / 99$ (39.4) & $1.3(0.8-2)$ & 0.338 & $1.3(0.7-2.2)$ & 0.413 \\
\hline $33 \mathrm{~F}$ & $3 / 11(27.3)^{\prime}$ & $0.7(0.2-2.8)$ & 0.635 & $0.8(0.2-3.9)$ & 0.781 \\
\hline $16 \mathrm{~F}$ & $52 / 121(43.0)$ & $1.5(1-2.2)$ & 0.083 & $1.6(1-2.7)$ & 0.066 \\
\hline $15 \mathrm{~A}$ & 42/104 (40.1) & $1.3(0.8-2)$ & 0.246 & $1.2(0.6-2)$ & 0.629 \\
\hline 13 & 19/71 (26.8) & $0.7(0.4-1.2)$ & 0.226 & $0.8(0.4-1.6)$ & 0.534 \\
\hline $7 \mathrm{C}$ & 20/59 (33.9) & $1(0.6-1.8)$ & 0.966 & $1.4(0.7-2.7)$ & 0.342 \\
\hline $35 B$ & 19/52 (36.5) & $1.1(0.6-2)$ & 0.738 & $1(0.5-2.1)$ & 0.922 \\
\hline $23 \mathrm{~A}$ & 19/62 (30.7) & $0.9(0.5-1.5)$ & 0.587 & $0.6(0.3-1.2)$ & 0.141 \\
\hline $6 \mathrm{C}$ & $11 / 34(32.4)$ & $0.9(0.4-2)$ & 0.830 & $0.8(0.3-2)$ & 0.590 \\
\hline \multicolumn{6}{|l|}{ Age group, y } \\
\hline $15-24$ & $86 / 282(30.5)$ & Referent & Referent & Referent & Referent \\
\hline $25-44$ & $549 / 1,738(31.6)$ & $1.1(0.8-1.4)$ & 0.714 & $1.2(0.8-1.7)$ & 0.392 \\
\hline $45-64$ & $385 / 917(42.0)^{\prime}$ & $1.6(1.2-2.2)$ & 0.001 & $2(1.4-2.9)^{\prime}$ & $<0.001$ \\
\hline$\geq 65$ & $107 / 240(44.6)$ & $1.8(1.3-2.6)$ & 0.001 & $3.1(1.8-5.2)$ & $<0.001$ \\
\hline \multicolumn{6}{|l|}{ Sex } \\
\hline $\mathrm{F}$ & $557 / 1,679$ (33.2) & Referent & Referent & Referent & Referent \\
\hline$M$ & $568 / 1,495(38.0)$ & $1.2(1.1-1.4)$ & 0.005 & $1.3(1.1-1.6)$ & 0.003 \\
\hline \multicolumn{6}{|l|}{ HIV status $†$} \\
\hline Negative & $154 / 556(27.7)$ & Referent & Referent & Referent & Referent \\
\hline Positive & $618 / 2,007(30.8)$ & $1.2(0.9-1.4)$ & 0.160 & $1.3(1-1.7)$ & 0.021 \\
\hline \multicolumn{6}{|l|}{ Diagnosis $\ddagger$} \\
\hline Nonmeningitis & $607 / 2,138(28.4)$ & Referent & Referent & Referent & Referent \\
\hline Meningitis & $520 / 1,039(50.1)$ & $2.5(2.2-2.9)$ & $<0.001$ & $2.8(2.3-3.4)$ & $<0.001$ \\
\hline \multicolumn{6}{|l|}{ Year } \\
\hline 2012 & 205/555 (36.9) & $1.4(1.1-1.8)$ & 0.013 & $1.1(0.8-1.5)$ & 0.549 \\
\hline 2013 & $144 / 486(29.6)$ & Referent & Referent & Referent & Referent \\
\hline 2014 & $143 / 407$ (35.1) & $1.3(1-1)$ & 0.08 & $1.1(0.8-1.5)$ & 0.626 \\
\hline 2015 & $177 / 465$ (38.1) & $1.5(1.1-1.9)$ & 0.006 & $1.4(1.0-2.0)$ & 0.031 \\
\hline 2016 & $168 / 449$ (37.4) & $1.4(1.1-1.9)$ & 0.012 & $1.3(0.9-1.8)$ & 0.106 \\
\hline 2017 & $159 / 447$ (35.6) & $1.3(1-1.7)$ & 0.053 & $1.3(0.9-1.8)$ & 0.140 \\
\hline 2018 & $131 / 368(35.6)$ & $1.3(1-1.8)$ & 0.065 & $1.4(1.0-1.9)$ & 0.082 \\
\hline
\end{tabular}

*Underlying medical conditions as a risk factor was analyzed but not significant in the univariate model. Empty fields indicate that the model did not calculate numbers due to small amount of data, or it was not included in the final multivariable model. Factors evaluated in the univariable model but not significant were race and province.

†HIV status was not significant upon initial multivariate analysis but was kept in the final analysis because of the high percentage of HIV positive cases in our study population $(78 \%)$

¥Meningitis cases include patients diagnosed with meningitis and those simultaneously diagnosed with meningitis and lower respiratory tract infection; nonmeningitis cases include all other cases. 
lineage as a result from a 19A capsule switch and van der Linden et al. (35) showed an increase in 15A after PCV-13 introduction in Germany. An increase of serogroup 15 in children with pneumococcal disease was noted in Hong Kong; Liyanapathirana et al. suggested consideration in future vaccine strategies (36). Because of these recent studies and the association we found with death, we suggest close monitoring of serogroup 15 in both adults and children.

Our study has limitations that make a direct comparison to other studies difficult. We used data from enhanced surveillance sites for available patient data; doing so excluded cases from smaller and rural hospitals and clinics. We also excluded from analysis cases for which serotype and outcome information were not available. Both limitations may have caused selection bias. Another limitation is that our 2 groups are not mutually exclusive; our analysis of IPD cases includes the meningitis cases, which we also analyzed separately as a subset. The inclusion of meningitis cases in the IPD analysis may be causing some of the serotypes to be associated with CFR. Temporal variation of serotypes after introduction of vaccines was not analyzed; although we considered the increase or decrease of serotypes in the conclusions, the consequences of these variations are hard to anticipate and may have introduced bias. In addition, we did not control for treatment or antimicrobial resistance, which may need to be studied in a future analysis. An advantage of this study is that, in an effort to detect differences in age groups, we analyzed the data in all ages as well as in 2 different age groups of $<15$ years and $\geq 15$ years. Another advantage is that we conducted the analysis to detect possible differences of serotype associated with death in IPD cases as well as in a subset of meningitis cases.

In conclusion, our data suggest that PCV13 serotypes 1, 3, 6A, 19A, and 19F should continue to be monitored in surveillance studies. Although we cannot exclude that other serotypes may also be important, we recommend inclusion of serotypes 8 and $12 \mathrm{~F}$ and serogroup 15 (serotypes 15A and 15B/C) in new vaccines, which may contribute to overall reduction of disease caused by S. pneumoniae.

\section{Acknowledgments}

We thank the participating patients, laboratory, and clinical staff (GERMS-SA investigators) for submitting case reports and isolates.

This work was supported by the Swiss-South African Joint Research Programme, funded by the Swiss National Science Foundation and the National Research Foundation of South Africa, to L.H. and A.v.G. (grant no. 170844). The funding body had no role in the design of the study or collection, analysis or interpretation of data or writing of the manuscript. C.C. received grant funds from US Centers for Disease Control and Prevention, South African MRC, Sanofi Pasteur, and PATH. A.v.G. received grant funds from Pfizer and Sanofi.

Author contributions: L.H. and A.v.G. conceived, designed, and coordinated the study. A.M. performed data analysis, prepared tables and graph, and drafted the manuscript. Data were collected by the GERMS-SA surveillance program. J.K., L.d.G., S.M., C.C. and A.v.G contributed to data collection. J.K. supported and helped with STATA analysis and provided the script for cleaning of data. L.d.G. and S.M. helped collect follow-up information for missing data and provided support for data questions. C.C. helped with the design of the study and provided support for statistical methods. L.H. helped draft the manuscript. All authors critically revised the manuscript and gave final approval for publication.

\section{About the Author}

Ms. Müller is a doctoral candidate at the Institute for Infectious Diseases, University of Bern, Switzerland. Her $\mathrm{PhD}$ project is an international collaboration together with the National Institute for Communicable Diseases, Johannesburg, South Africa, focused on the virulence of pneumococcal serotypes.

\section{References}

1 Örtqvist A, Hedlund J, Kalin M. Streptococcus pneumoniae: epidemiology, risk factors, and clinical features. Semin Respir Crit Care Med. 2005;26:563-74. https://doi.org/ 10.1055/s-2005-925523

2. Hurley D, et al. Safety, tolerability, and immunogenicity of a 20 -valent pneumococcal conjugate vaccine (PCV20) in adults 60 to 64 years of age. Clin Infect Dis. 2021;73:e1489-97.

3. Rupp R, Hurley D, Grayson S, Li J, Nolan K, McFetridge RD, et al. A dose ranging study of 2 different formulations of 15-valent pneumococcal conjugate vaccine (PCV15) in healthy infants. Hum Vaccin Immunother. 2019;15:549-59. https:/ / doi.org/10.1080/21645515.2019.1568159

4. Clarke E, Bashorun AO, Okoye M, Umesi A, Badjie Hydara M, Adigweme I, et al. Safety and immunogenicity of a novel 10-valent pneumococcal conjugate vaccine candidate in adults, toddlers, and infants in The Gambia - results of a phase 1/2 randomized, double-blinded, controlled trial. Vaccine. 2020;38:399-410. https:/ / doi.org/10.1016/ j.vaccine.2019.08.072

5. Weinberger DM, Shapiro ED. Pneumococcal vaccines for adults: what's next? Clin Infect Dis. 2020;70:2493-5. https://doi.org/10.1093/cid/ciz743

6. Balsells E, Guillot L, Nair H, Kyaw MH. Serotype distribution of Streptococcus pneumoniae causing invasive disease in children in the post-PCV era: A systematic review and meta-analysis. PLoS One. 2017;12:e0177113. https://doi.org/10.1371/journal.pone.0177113 
7. Weinberger DM, Malley R, Lipsitch M. Serotype replacement in disease after pneumococcal vaccination. Lancet. 2011; 378:1962-73. https:// doi.org/10.1016/S0140-6736(10)62225-8

8. Fleming-Dutra KE, Conklin L, Loo JD, Knoll MD, Park DE, Kirk J, et al. Systematic review of the effect of pneumococcal conjugate vaccine dosing schedules on vaccine-type nasopharyngeal carriage. Pediatr Infect Dis J. 2014;33(Suppl 2):S152-60. https:/ / doi.org/10.1097/INF.0000000000000083

9. Cohen C, Naidoo N, Meiring S, de Gouveia L, von Mollendorf C, Walaza S, et al.; GERMS-SA. Streptococcus pneumoniae serotypes and mortality in adults and adolescents in South Africa: analysis of national surveillance data, 2003-2008. PLoS One. 2015;10:e0140185. https:/ / doi.org/ 10.1371/journal.pone. 0140185

10. von Gottberg A, Cohen C, de Gouveia L, Meiring S, Quan V, Whitelaw A, et al. Epidemiology of invasive pneumococcal disease in the pre-conjugate vaccine era: South Africa, 20032008. Vaccine. 2013;31:4200-8. https:// doi.org/10.1016/ j.vaccine.2013.04.077

11. Iroh Tam PY, Thielen BK, Obaro SK, Brearley AM, Kaizer AM, $\mathrm{Chu} \mathrm{H}$, et al. Childhood pneumococcal disease in Africa-a systematic review and meta-analysis of incidence, serotype distribution, and antimicrobial susceptibility. Vaccine. 2017;35:1817-27. https://doi.org/10.1016/j.vaccine.2017.02.045

12. Balsells E, Dagan R, Yildirim I, Gounder PP, Steens A, Muñoz-Almagro $C$, et al. The relative invasive disease potential of Streptococcus pneumoniae among children after PCV introduction: a systematic review and meta-analysis. J Infect. 2018;77:368-78. https:/ / doi.org/10.1016/j.jinf.2018.06.004

13. Croucher NJ, Løchen A, Bentley SD. Pneumococcal vaccines: host interactions, population dynamics, and design principles. Annu Rev Microbiol. 2018;72:521-49. https://doi.org/10.1146/annurev-micro-090817-062338

14. Grabenstein JD, Musey LK. Differences in serious clinical outcomes of infection caused by specific pneumococcal serotypes among adults. Vaccine. 2014;32:2399-405. https:/ / doi.org/10.1016/j.vaccine.2014.02.096

15. Hathaway LJ, Grandgirard D, Valente LG, Täuber MG, Leib SL. Streptococcus pneumoniae capsule determines disease severity in experimental pneumococcal meningitis. Open Biol. 2016;6:150269. https:/ / doi.org/10.1098/rsob.150269

16. Jacques LC, Panagiotou S, Baltazar M, Senghore M, Khandaker S, Xu R, et al. Increased pathogenicity of pneumococcal serotype 1 is driven by rapid autolysis and release of pneumolysin. Nat Commun. 2020;11:1892. https:/ / doi.org/10.1038/s41467-020-15751-6

17. Song JY, Nahm MH, Moseley MA. Clinical implications of pneumococcal serotypes: invasive disease potential, clinical presentations, and antibiotic resistance. J Korean Med Sci. 2013;28:4-15. https://doi.org/10.3346/jkms.2013.28.1.4

18. Venkateswaran PS, Stanton N, Austrian R. Type variation of strains of Streptococcus pneumoniae in capsular serogroup 15. J Infect Dis. 1983;147:1041-54. https://doi.org/10.1093/ infdis/147.6.1041

19. Cohen C, Naidoo N, Meiring S, de Gouveia L, von Mollendorf C, Walaza S, et al.; GERMS-SA. Streptococcus pneumoniae serotypes and mortality in adults and adolescents in South Africa: analysis of national surveillance data, 20032008. PLoS One. 2015;10:e0140185. https://doi.org/10.1371/ journal.pone.0140185

20. Antonio M, Hakeem I, Awine T, Secka O, Sankareh K, Nsekpong D, et al. Seasonality and outbreak of a predominant Streptococcus pneumoniae serotype 1 clone from The Gambia: expansion of ST217 hypervirulent clonal complex in West Africa. BMC Microbiol. 2008;8:198. https:/ / doi.org/ 10.1186/1471-2180-8-198
21. Le Hello S, Watson M, Levy M, Marcon S, Brown M, Yvon JF, et al. Invasive serotype 1 Streptococcus pneumoniae outbreaks in the South Pacific from 2000 to 2007. J Clin Microbiol. 2010;48:2968-71. https://doi.org/10.1128/ JCM.01615-09

22. Martens P, Worm SW, Lundgren B, Konradsen HB, Benfield T. Serotype-specific mortality from invasive Streptococcus pneumoniae disease revisited. BMC Infect Dis. 2004;4:21. https://doi.org/10.1186/1471-2334-4-21

23. Burgos J, Falcó V, Borrego A, Sordé R, Larrosa MN, Martinez X, et al. Impact of the emergence of non-vaccine pneumococcal serotypes on the clinical presentation and outcome of adults with invasive pneumococcal pneumonia. Clin Microbiol Infect. 2013;19:385-91. https:// doi.org/10.1111/j.1469-0691.2012.03895.x

24. Weinberger DM, Harboe ZB, Sanders EA, Ndiritu M, Klugman KP, Rückinger S, et al. Association of serotype with risk of death due to pneumococcal pneumonia: a meta-analysis. Clin Infect Dis. 2010;51:692-9. https:/ / doi.org/ $10.1086 / 655828$

25. Varon E, Cohen R, Béchet S, Doit C, Levy C. Invasive disease potential of pneumococci before and after the 13-valent pneumococcal conjugate vaccine implementation in children. Vaccine. 2015;33:6178-85. https://doi.org/10.1016/ j.vaccine.2015.10.015

26. Brueggemann AB, Peto TE, Crook DW, Butler JC, Kristinsson KG, Spratt BG. Temporal and geographic stability of the serogroup-specific invasive disease potential of Streptococcus pneumoniae in children. J Infect Dis. 2004;190:1203-11. https:/ / doi.org/10.1086/ 423820

27. Johnson HL, Deloria-Knoll M, Levine OS, Stoszek SK, Freimanis Hance L, Reithinger R, et al. Systematic evaluation of serotypes causing invasive pneumococcal disease among children under five: the pneumococcal global serotype project. PLoS Med. 2010;7:e1000348. https:/ / doi.org/ 10.1371/journal.pmed.1000348

28. du Plessis M, Allam M, Tempia S, Wolter N, de Gouveia L, von Mollendorf $\mathrm{C}$, et al. Phylogenetic analysis of invasive serotype 1 pneumococcus in South Africa, 1989 to 2013. J Clin Microbiol. 2016;54:1326-34. https:/ / doi.org/10.1128/ JCM.00055-16

29. von Mollendorf C, Cohen C, Tempia S, Meiring S, de Gouveia L, Quan V, et al.; Group for Enteric, Respiratory, and Meningeal Disease Surveillance in South Africa (GERMS-SA). Epidemiology of serotype 1 invasive pneumococcal disease, South Africa, 2003-2013. Emerg Infect Dis. 2016;22:261-70. https://doi.org/10.3201/ eid2202.150967

30. Harboe ZB, Thomsen RW, Riis A, Valentiner-Branth $\mathrm{P}$, Christensen JJ, Lambertsen L, et al. Pneumococcal serotypes and mortality following invasive pneumococcal disease: a population-based cohort study. PLoS Med. 2009;6:e1000081. https://doi.org/10.1371/journal.pmed.1000081

31. Tan TQ. Pediatric invasive pneumococcal disease in the United States in the era of pneumococcal conjugate vaccines. Clin Microbiol Rev. 2012;25:409-19. https:// doi.org/ 10.1128/CMR.00018-12

32. Løchen A, Croucher NJ, Anderson RM. Divergent serotype replacement trends and increasing diversity in pneumococcal disease in high income settings reduce the benefit of expanding vaccine valency. Sci Rep. 2020;10:18977. https:/ / doi.org/10.1038/s41598-020-75691-5

33. Cui YA, Patel H, O’Neil WM, Li S, Saddier P. Pneumococcal serotype distribution: a snapshot of recent data in pediatric and adult populations around the world. Hum Vaccin 
Immunother. 2017;13:1229-1241. https:/ / doi.org/10.1080/ 21645515.2016.1277300

34. Savinova T, Brzhozovskaya E, Shagin D, Mikhaylova Y, Shelenkov A, Yanushevich Y, et al. A multiple drug-resistant Streptococcus pneumoniae of serotype 15A occurring from serotype 19A by capsular switching. Vaccine. 2020;38:5114-8. https://doi.org/10.1016/j.vaccine.2020.05.075

35. van der Linden M, Perniciaro S, Imöhl M. Increase of serotypes 15A and 23B in IPD in Germany in the PCV13 vaccination era. BMC Infect Dis. 2015;15:207. https:/ / doi.org/10.1186/ s12879-015-0941-9
36. Liyanapathirana V, Nelson EA, Ang I, Subramanian R, Ma H, Ip M. Emergence of serogroup 15 Streptococcus pneumoniae of diverse genetic backgrounds following the introduction of pneumococcal conjugate vaccines in Hong Kong. Diagn Microbiol Infect Dis. 2015;81:66-70. https:/ / doi.org/10.1016/j.diagmicrobio.2014.09.028

Address for correspondence: Annelies Müller, Institute for Infectious Diseases, University of Bern, Friedbühlstrasse 51, 3001 Bern, Switzerland; email: annelies.mueller@ifik.unibe.ch

\section{November 2020} Respiratory Infections

- The Problem of Microbial Dark Matter in Neonatal Sepsis

- Two Pandemics, One ChallengeLeveraging Molecular Test Capacity of Tuberculosis Laboratories for Rapid COVID-19 Case-Finding

- Measuring Timeliness of Outbreak Response in the World Heath Organization African Region, 2017-2019

- Challenges to Achieving Measles Elimination, Georgia, 2013-2018

- Phage-Mediated Immune Evasion and Transmission of Livestock-Associated Methicillin-Resistant Staphylococcus aureus in Humans

- Validated Methods for Removing Select Agent Samples from Biosafety Level 3 Laboratories

- Epidemiology of COVID-19 Outbreak on Cruise Ship Quarantined at Yokohama, Japan, February 2020

- Expert Taskforce for the COVID-19 Cruise Ship Outbreak

- Analysis of SARS-CoV-2 Transmission in Different Settings, Brunei

- Case-Control Study of Use of Personal Protective Measures and Risk for SARS-CoV-2 Infection, Thailand

- Transmission of SARS-CoV-2 During Long-Haul Flight

- Nowcasting (Short-Term Forecasting) of Influenza Epidemics in Local Settings, Sweden, 2008-2019 A. Spreco et al. 2670

- Epileptic Seizure after Use of Moxifloxacin in Man with Legionella longbeachae Pneumonia

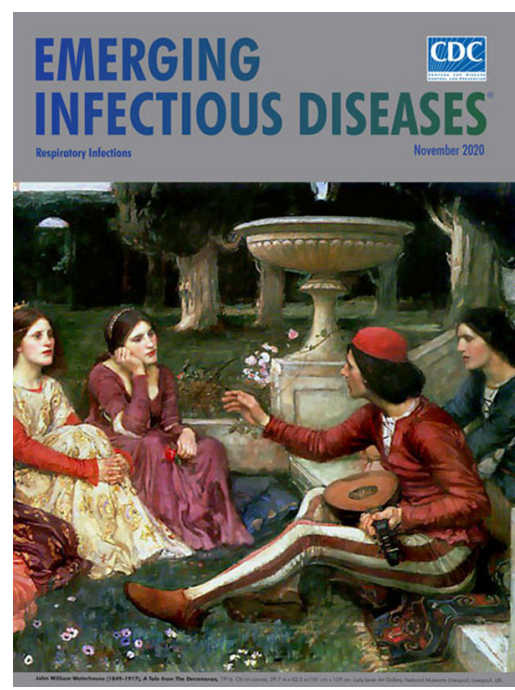

- High Dengue Burden and Circulation of 4 Virus Serotypes among Children with Undifferentiated Fever, Kenya, 2014-2017

- Endotheliopathy and Platelet Dysfunction as Hallmarks of Fatal Lassa Fever

- Systematic Review and Meta-Analyses of Incidence for Group B Streptococcus Disease in Infants and Antimicrobial Resistance, China

- Streptococcus pneumoniae Serotype 12F-CC4846 and Invasive Pneumococcal Disease after Introduction of 13-Valent Pneumococcal Conjugate Vaccine, Japan, 2015-2017

- Azithromycin to Prevent Pertussis in Household Contacts, Catalonia and Navarre, Spain, 2012-2013
- Modeling Treatment Strategies to Inform Yaws Eradication

- Multidrug-Resistant Candida auris Infections in Critically Ill Coronavirus Disease Patients, India, April-July 2020

- Potential Role of Social Distancing in Mitigating Spread of Coronavirus Disease, South Korea

- SARS-CoV-2 Virus Culture and Subgenomic RNA for Respiratory Specimens from Patients with Mild Coronavirus Disease

- Asymptomatic Transmission of SARS-CoV-2 on Evacuation Flight

- Worldwide Effects of Coronavirus Disease Pandemic on Tuberculosis Services, January-April 2020

- In-Flight Transmission of SARS-CoV-2

- Preventing Vectorborne Transmission of Zika Virus Infection During Pregnancy, Puerto Rico, USA, 2016-2017

- Multidrug-Resistant Hypervirulent Group B Streptococcus in Neonatal Invasive Infections, France, 2007-2019

- Two New Cases of Pulmonary Infection by Mycobacterium shigaense

- Thresholds versus Anomaly Detection for Surveillance of Pneumonia and Infwluenza Mortality

- Multiple Introductions of Salmonella enterica Serovar Typhi H58 with Reduced Fluoroquinolone Susceptibility into Chile

- Chikungunya Virus Infection in Blood Donors and Patients During Outbreak, Mandalay, Myanmar, 2019 